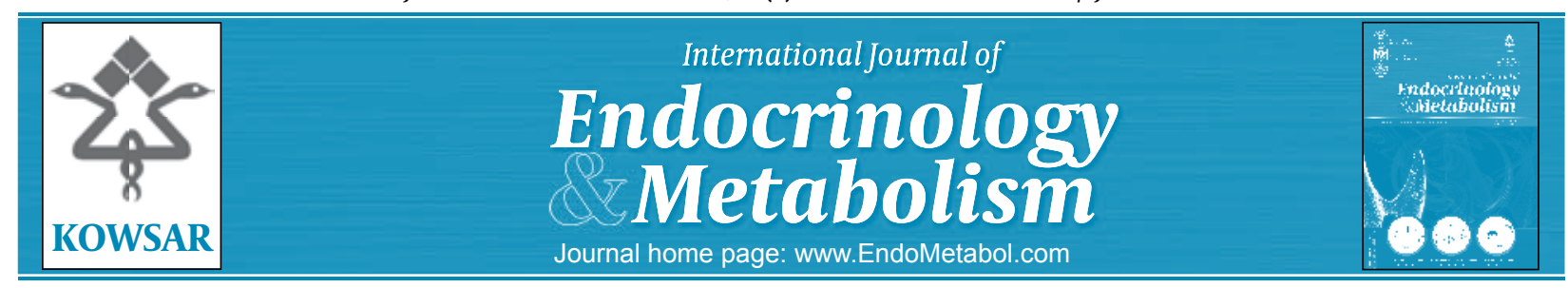

\title{
Ethnicity, Smoking and Body Composition Influence Testosterone and Estradiol Levels in Healthy Young Adult Men in Malaysia: A Pilot Study
}

\author{
Kok Yong Chin ${ }^{1}$, Ima Nirwana Soelaiman ${ }^{1^{*}}$, Isa Naina Mohamed ${ }^{1}$, Hanapi Johari ${ }^{2}$, Wan \\ Zurinah Wan Ngah $^{2}$ \\ ${ }^{1}$ Pharmacology Department, Faculty of Medicine, Universiti Kebangsaan Malaysia, Kuala Lumpur Malaysia \\ 2 Biochemistry Department, Faculty of Medicine, Universiti Kebangsaan Malaysia, Kuala Lumpur, Malaysia
}

\begin{tabular}{l}
\hline A R T I C L E I N F O \\
\hline Article type: \\
Original Article \\
\hline Article history: \\
Received: 28 Nov 2011 \\
Accepted: 01 Jan 2012 \\
Revised: 02 Jan 2012 \\
\hline
\end{tabular}

Keywords:

Sex Hormones

Testosterone

Estradiol

Smoking

Body Composition

\begin{abstract}
A B S T R A C T
Background: Variations in sex hormone levels can be caused by differences in ethnicity, smoking habits, and body composition and may be related to racial differences in the prevalence of certain diseases.

Objectives: This study examined the effects of ethnicity, smoking, and body composition on testosterone and estradiol levels in a group of young Malaysian men.

Patients and Methods: In this cross-sectional study, 189 Malay and Chinese men aged 20-39 years answered a detailed questionnaire, underwent body anthropometric measurements, and had their blood drawn for hormone assays.

Results: The results indicated no differences in testosterone levels between races $(P>0.05)$, but estradiol levels were significantly higher among Malay compared with Chinese men $(P<$ $0.05)$. No difference was detected in sex hormone levels between smokers and non-smokers $(P>0.05)$. However, smokers with more than 10 years of cigarette smoke exposure had a significantly higher estradiol level than smokers with $1-5$ years of exposure $(\mathrm{P}<0.05)$. Testosterone (total, free, and non-SHBG-bound) levels correlated inversely and significantly $(P<0.05)$ with body mass index (BMI), waist-to-hip circumference ratio (WHR), and percentage of body fat. By multiple stepwise regression, body fat percentage was the most influential predictor of testosterone ( $\beta=-0.456$ for total, $\beta=-0.279$ for free, $\beta=-0.297$ for non-SHBG-bound fraction) and SHBG levels ( $\beta=-0.172)$.

Conclusions: Estradiol levels are influenced by ethnicity and duration of smoking, whereas testosterone levels are governed by body fat percentage in Malaysian young adult males.
\end{abstract}

Copyright $\odot 2012$ Kowsar M. P. Co. All rights reserved.

Implication for health policy/practice/research/medical education:

The factors that influence sex hormone levels suggested in this study may explain the differences in the prevalence of disease in populations with distinct demographics and behavior. It also suggests possible areas for behavior modification in order to prevent sex hormone dependent diseases from developing.

Please cite this paper as:

Chin KY, Soelaiman IN, Mohamed IN, Joharj H, Wan Ngah WZ. Ethnicity, Smoking and Body Composition Influence Testosterone and Estradiol Levels in Healthy Young Adult Men in Malaysia: A Pilot Study. Int J Endocrinol Metab. 2012; 10(1): 404-10. DOI: 10.5812/ ijem.3937

* Corresponding author: Ima Nirwana Soelaiman, Department of Pharmacology, Faculty of Medicine, University Kebangsaan Malaysia, Jalan Raja Muda Abdul Aziz, 50300 Kuala Lumpur, Malaysia. Tel: +60-340405514, Fax: +60-326938205, E-mail: imasoel@medic.ukm.my

DOI:10.5812/ijem.3937

Copyright @2012 Kowsar M. P. Co. All rights reserved.

\section{Background}

Variations in sex hormone levels in men have important implications for their health. Sex hormones are associated with various diseases, such as osteoporosis (1-3), fractures $(2,4,5)$, cardiovascular diseases $(6,7)$, cancers $(8)$, and insulin resistance $(9,10)$. Thus, it is important to identify the factors that influence the levels of these 
hormones, which can explain the differences in the prevalence of diseases in populations with distinct demographics and behaviors. Furthermore, if the factors that are associated with alterations in sex hormones are avoidable (such as smoking and obesity), behavior modifications can be initiated early to prevent diseases from developing later in.

Previous studies have indicated that ethnicity contributes to variations in sex hormone levels in a population. A large international study by Orwell et al. (2010) noted considerable differences in sex hormone levels in elderly men of various ethnic and geographical backgrounds (11). In most other studies, comparisons have been made between African-Americans and Caucasians $(12,13)$. The 2010 census revealed that the Malaysian population consists of Malays (67.4\%), Chinese (24.6\%), Indians (7.3\%), and other minorities (0.7\%) (http://www.statistics.gov. my), but the differences between Asian ethnic groups that live in the same country, such as Malaysia, have not been examined. In this study, Malays and Chinese were selected for comparison, because they are the 2 largest ethnic groups in Malaysia.

Smoking is a potential confounding factor that contributes to variations in sex hormone levels. No consensus has been reached regarding the effect of smoking on sex hormones, wherein reduced (14), elevated (15-17), and constant (18-20) levels of testosterone in smokers versus non-smokers have been reported. Further, smoking has been associated with cardiovascular disease (21), which is also linked to alterations in sex hormone levels $(6,7)$.

Body composition, especially adiposity, causes variations in sex hormones levels in men. Adiposity has been linked to insulin resistance, which is also associated with alterations in sex hormones (10). Previous studies have used waist circumference or waist-to-hip circumference ratio (WHR) (22) and body mass index (BMI) $(23,24)$ to assess adiposity. We sought to confirm these studies using a novel and simple technique, based on bioelectrical impedance, to determine the percentage of body fat and WHR in subjects.

\section{Objectives}

The objective of this study was to determine the effects of ethnicity, smoking, and body composition on sex hormone levels in a group of Malaysian men aged 20-39 years. Currently, there is no literature on the differences in sex hormone levels between ethnic groups in Malaysia or the factors that contribute to such variation. Young adults were enrolled as subjects to determine whether differences in ethnicity, smoking, and body composition influence sex hormone levels in early adulthood.

\section{Patients and Methods}

\subsection{Study Design}

This study was conducted as a part of the Malaysian Aging Male Study, which aimed to examine the hormonal, oxidative, nutritional, and bone health status of Malay and Chinese men residing in the urbanized central part of peninsular Malaysia. It was a cross-sectional study, for which a purposive sampling method was adopted, as described (25). Briefly, subjects were recruited via advertisements in major newspapers, flyers, radio broadcasts, and public announcements at various community centers and mosques. The selection criteria were stated clearly in the advertisements. Subjects were advised to bring their medical reports, and a qualified physician screened the subjects, based on a medical history and physical examination. The study was approved by the Ethics Committee of Universiti Kebangsaan Malaysia Medical Centre (UK$\mathrm{MMC})$.

\subsection{Subjects}

The recruitment was conducted from January 2011 to June 2011. Two hundred six Malaysian men of Chinese and Malay ethnicity aged 20-39 years who resided in the central region of peninsular Malaysia (Kuala Lumpur, Gombak, and Klang) were recruited. The 20-39-year age range was defined as 'young adult,' because other studies in Malaysia have referred to 'middle-age' as those aged 40 years and above (26). All information pertaining to this study was explained to them, and written informed consent was obtained. They were screened using a detailed questionnaire. Their medical history was taken, and a physical examination was performed by an experienced physician. The exclusion criteria for the subjects were the same as those of the Malaysian Aging Male Study, in which persons who suffered from chronic diseases that affected major systems of the body, such as hormonal abnormalities, osteoporosis, cardiovascular diseases, and cancers, were excluded, because these diseases are associated with alterations in sex hormone levels. Subjects who were taking long-term medications were also excluded, because they could have affected sex hormone levels.

\subsection{Smoking Habits}

Subjects were categorized as smokers, ex-smokers, and non-smokers. A smoker was defined as a person who had been smoking daily and was still doing so at the time of the examination; an ex-smoker had been smoking but had ceased doing so for the past 6 months; and a non-smoker was a person who had never smoked. Smokers were asked to record their duration of smoking in years (27).

\subsection{Body Composition}

The standing height of subjects without shoes was measured using a portable stadiometer and recorded to the nearest $0.1 \mathrm{~cm}$. The weight of the subjects in light clothing without shoes was recorded to the nearest 0.1 $\mathrm{kg}$. Body mass index of subjects was calculated per the formula: BMI $\left(\mathrm{kg} / \mathrm{m}^{2}\right)$ = body weight $(\mathrm{kg}) /$ (height $\mathrm{x}$ 
height) $\left(\mathrm{m}^{2}\right)$. Waist circumference was measured using a soft measuring tape midway between the lowest rib margin and the iliac crest in the standing position. Hip circumference was measured over the widest part of the gluteal region. The waist-hip circumference ratio (WHR) was then calculated.

The percentage of body fat was estimated using a BC-418 Segmental Body Composition Analyzer (Tanita, Illinois, USA). Estimation of body fat was based on the principle of bioelectrical impedance using a constant current source with high-frequency current $(50 \mathrm{kHz}$, $500 \mathrm{~A}$ ). The subjects were required to step on the platform, touch the electrodes with their bare feet, and maintain a stable standing position. They were also requested to grab handgrips while the impedance was measured. The electric current flowed through their bodies via electrodes at the toes of both feet and the fingertips of both hands. Voltage was measured at the heel of both feet and the thenar side of both hands. The fat in the body does not allow electricity to pass through, whereas water in the muscle tissue does. The degree of difficulty with which the electricity passed was used to infer the percentage of body fat.

\subsection{Measurement of Sex Hormones}

All subjects were requested to fast for at least 8 hours prior to attending the data collection session. During the fasting period, they were allowed to consume only water. Venipuncture was performed between 900 and 1030. Their blood was collected in plain tubes, and serum was extracted. Part of the serum was sent immediately to measure testosterone, estradiol, and albumin, and the remaining serum was stored in polypropylene tubes at $-70^{\circ} \mathrm{C}$ for sex hormone-binding globulin (SHBG) measurements. The serum was stored 0-3 months.

Total testosterone and total estradiol levels were measured using the ADVIA Centaur (Siemens Healthcare Diagnostics, Illinois, USA), based on competitive immunoassay with direct chemiluminescent technology. Non-SHBG-bound and free fractions of sex hormones were calculated per Södergård et al. (1982) (28). The albumin level was measured using the ADVIA 2400 (Siemens Healthcare Diagnostics, Illinois, USA), based on a colorimetric method (bromcresol green method). SHBG level was determined using solid phase enzyme-linked immunosorbent assay (ELISA) kits, based on the sandwich principle (IBL International, Hamburg, Germany). The test principles and procedures were performed per the manufacturers. The interassay coefficient of variation (CV) for the total testosterone, total estradiol, albumin, and SHBG assays were 1.79\%-6.32\%, 1.99\%-2.03\%, 1.37\%-1.70\%, and $7.2 \%-11.6 \%$, respectively

\subsection{Data Analysis}

The values for sex hormones were expressed as mean [standard deviation (SD) ] if the distribution was normal and as median [interquartile range (IQR) ] if the distribution was skewed. Normality of the data was examined by Kolmogorov-Smirnov test. Transformation for skewed data was attempted, and normalized values were used for statistical analysis. If transformation did not improve the normality of the data, non-parametric tests were used to analyze them. Differences between Chinese and Malay men were analyzed by independent t-test for normal data and Mann-Whitney U test for skewed data. Similarly, differences between smokers and non-smokers were analyzed independent t-test for normal data and Mann-Whitney U test for skewed data. Smokers were stratified into 3 groups according to how long they had smoked: $1-5$ years, $>$ 5-10 years and $>10$ years. Differences between groups were compared by one-way analysis of variance (ANOVA) for normal data and Kruskal-Wallis test for skewed data.

Correlations between all parameters were examined using Pearson's correlation for normal data and Spearman's correlation for skewed data. The strength of the correlation was indicated by Pearson's correlation coefficient $(r)$ or Spearman's correlation coefficient $\left(r_{s}\right)$. Multiple regression analysis was used to evaluate the relationship between each sex hormone and individual anthropometric parameters (BMI, WHR, percentage of body fat). Standardized regression coefficient $(\beta)$ was used to compare the contribution of each predictor in the regression model, describing the extent of SD change in sex hormones when the predictors of interest changed by 1 SD while the other predictors were held constant. $\mathrm{R}^{2}$ of the equation was also shown to indicate the percentage of variation in sex hormones that could be explained by the equations that were generated. The statistical significance was set to $P<0.05$. The results were analyzed using SPSS for Windows, version 16.0 (SPSS Inc., Chicago, Illinois).

\section{Results}

Two hundred six Chinese and Malay men aged 20-39 years volunteered for this study. One hundred eightynine (91.75\%) successfully underwent all the necessary screens and completed the required questionnaires, body composition assessments, and venipuncture. Seventeen subjects were excluded-3 men did not complete the questionnaire, and 14 men failed to visit for a com-

\begin{tabular}{llll}
\hline \multicolumn{3}{l}{ Table 1. Demographic and Anthropometric } & \multicolumn{3}{l}{ Characteristics of Subjects } \\
\hline & $\begin{array}{l}\text { Malay } \\
(\mathbf{9 9})\end{array}$ & $\begin{array}{l}\text { Chinese } \\
(\mathbf{9 0})\end{array}$ & $\begin{array}{l}\text { Overall } \\
(\mathbf{1 8 9})\end{array}$ \\
\hline Age $^{\mathrm{b}}, \mathrm{y}$ & $25.6 \pm 5.5$ & $30.1 \pm 5.7 \mathrm{a}$ & $27.8 \pm 6.0$ \\
Height $^{\mathrm{b}}, \mathrm{cm}$ & $167.7 \pm 5.8$ & $171.2 \pm 5.8^{\mathrm{a}}$ & $169.4 \pm 6.0$ \\
Weight $^{\mathrm{b}}, \mathrm{kg}$ & $66.8 \pm 13.6$ & $70.9 \pm 17.7$ & $68.7 \pm 14.7$ \\
BMI $^{\mathrm{b}}, \mathrm{kg} / \mathrm{m}^{2}$ & $23.7 \pm 4.3$ & $24.1 \pm 4.7$ & $23.9 \pm 4.5$ \\
Waist to hip ratio $^{\mathrm{b}}$ & $0.87 \pm 0.06$ & $0.89 \pm 0.05^{\mathrm{a}}$ & $0.88 \pm 0.05$ \\
Body fat $^{\mathrm{b}}, \%$ & $20.6 \pm 6.5$ & $21.0 \pm 6.6)$ & $20.8 \pm 6.5$ \\
\hline
\end{tabular}

\footnotetext{
a Indicates significant difference between the Chinese and Malay men.
}

${ }^{\mathrm{b}}$ Data are Presented as Mean \pm SD 
plete blood test. Ninety-nine (52.4\%) subjects were Malay, and 90 (47.6\%) were Chinese men. Their mean age was 27.8 years $(\mathrm{SD}=6.0$ years $)$ (Table 1$)$.

All testosterone levels were tested normal in terms of normality (Kolmogorov-Smirnov test with $P>0.05$ ), but all estradiol and SHBG levels were skewed. Transformations (square root, $\log _{10}$, inverse) were attempted, but they only improved the skewness, not the kurtosis of the estradiol levels. Hence, they were analyzed using nonparametric tests. The distribution of SHBG reverted to normal after square root transformation was attempted and was used in the data analysis.

There was a significant difference in age and height $(P<$ 0.05) between Malays and Chinese; the Chinese were older and taller. The Chinese also had significantly higher WHRs $(P<0.05)$ compared with Malays. No other significant differences in body anthropometry were observed between the groups (Table 1). The differences in total, free, and non-SHBG-bound testosterone between the Chinese and Malays were not significant $(P>0.05)$. However, significant differences $(P>0.05)$ in the total, free, and nonSHBG estradiol levels were noted between groups, attributed to estradiol levels alone rather than SHBG levels, because there was no significant difference $(P<0.05)$ in SHBG levels between the groups (Table 2).

Sixty-three subjects were smokers, and 116 were nonsmokers. Seven subjects identified themselves as exsmokers, and 3 chose not to disclose their smoking habits. Only the data of smokers and non-smokers were included in this analysis. No significant differences $(P>$ $0.05)$ were observed in any hormone between smokers and non-smokers (Table 2).

Smokers were stratified according to how long they smoked [1-5 years $(n=16),>5-10$ years $(n=22)$ and more than 10 years $(n=29)$ ], and differences in hormone levels were examined. No significant difference $(P<0.05)$ in total, free, or non-SHBG-bound testosterone; non-SHBGbound estradiol; or SHBG was noted. Differences in total estradiol and free estradiol between groups were marginally significant $(P=0.035$ for total estradiol, $P=0.043$ for free estradiol). Subjects with a history of smoking of more than 10 years had significantly higher $(P<0.05)$ total and free estradiol levels than subjects with 1-5 years of smoking history (Table 2).

Bivariate correlation analysis revealed significant negative correlations $(P<0.05)$ between total testosterone and weight, BMI, percentage of body fat, and WHR, although the strength of the correlations was moderate. Similarly, significant negative correlations $(P<0.05)$ were observed between free and non-SHBG-bound testosterone with weight, BMI, percentage of body fat, and WHR, but the strength of the correlation was smaller than the correlation with total testosterone. On adjusting for age, the significance between WHR and all testosterone levels was lost $(P>0.05)$.

Total estradiol correlated negatively and significantly with BMI, WHR, and percentage of body fat, but the strength of the correlations was small. Free and nonSHBG-bound free estradiol did not correlate with any anthropometric parameter. SHBG correlated significantly $(P<0.05)$ with all anthropometric parameters, and the significance persisted after adjustments for age (Table 3). When BMI, WHR, and percentage of body fat were selected as predictors of testosterone (total, free and bioavailable) and SHBG (transformed) in the stepwise regression analysis, the percentage of body fat was determined to be the most influential predictor for each of the equations, explained $20.8 \%$ of the variation in total testoster-

\begin{tabular}{|c|c|c|c|c|c|c|c|c|}
\hline & \multicolumn{3}{|c|}{ Ethnicity } & \multicolumn{2}{|c|}{ Smoking Status } & \multicolumn{3}{|c|}{ Duration of Exposure to Cigarette Smoke } \\
\hline & Malay & Chinese & Overall & Non-Smoker & Smoker & 1-5 Years & $>5-10$ Years & $>10$ Years \\
\hline $\begin{array}{l}\text { Total testosterone }{ }^{\mathrm{c}} \text {, } \\
\mathrm{nmol} / \mathrm{L}\end{array}$ & $20.4 \pm 6.4$ & $19.3 \pm 6.4$ & $19.9 \pm 6.4$ & $19.9 \pm 6.2$ & $20.1 \pm 6.9$ & $19.5 \pm 4.9$ & $22.0 \pm 8.4$ & $18.7 \pm 6.1$ \\
\hline $\begin{array}{l}\text { Free testosterone }{ }^{c} \text {, } \\
\text { nmol/L }\end{array}$ & $0.43 \pm 0.12$ & $0.42 \pm 0.12$ & $0.43 \pm 0.12$ & $0.43 \pm 0.12$ & $0.43 \pm 0.13$ & $0.41 \pm 0.11$ & $0.46 \pm 0.15$ & $0.40 \pm 0.11$ \\
\hline $\begin{array}{l}\text { Non-SHBG bound } \\
\text { testosterone }{ }^{\mathrm{c}} \text {, } \\
\mathrm{nmol} / \mathrm{L}\end{array}$ & $12.6 \pm 3.5$ & $12.1 \pm 3.6$ & $12.4 \pm 3.6$ & $12.6 \pm 3.6$ & $12.3 \pm 3.5$ & $11.9 \pm 3.1$ & $13.4 \pm 4.1$ & $11.5 \pm 3.0$ \\
\hline $\begin{array}{l}\text { Total estradiol, } \\
\text { pmol/L, IQR }\end{array}$ & $120.0 \pm 74.0$ & $65.5 \pm 111.3^{a}$ & $104.0 \pm 96.5$ & $115.5 \pm 92.3$ & $86.0 \pm 103.0$ & $147.5 \pm 86.0$ & $86.5 \pm 103.0$ & $75.0 \pm 97.5^{b}$ \\
\hline $\begin{array}{l}\text { Free estradiol, } \\
\text { pmol/L, IQR }\end{array}$ & $2.74 \pm 2.02$ & $1.74 \pm 2.57^{\mathrm{a}}$ & $2.55 \pm 2.41$ & $2.67 \pm 2.37$ & $2.18 \pm 2.36$ & $3.57 \pm 2.06$ & $2.23 \pm 2.16$ & $1.75 \pm 2.09^{b}$ \\
\hline $\begin{array}{l}\text { Non-SHBG bound } \\
\text { estradiol, pmol/L, } \\
\text { IQR }\end{array}$ & $85.1 \pm 60.2$ & $51.1 \pm 81.4^{\mathrm{a}}$ & $73.9 \pm 74.0$ & $84.4 \pm 72.5$ & $64.7 \pm 76.3$ & $108.9 \pm 66.5$ & $63.4 \pm 65.5$ & $50.9 \pm 60.5$ \\
\hline $\begin{array}{l}\text { Sex-hormone } \\
\text { binding globulin, } \\
\text { nmol/L, IQR }\end{array}$ & $36.4 \pm 22.8$ & $32.9 \pm 22.7$ & $35.5 \pm 22.4$ & $31.4 \pm 21.5$ & $37.3 \pm 25.8$ & $37.6 \pm 23.9$ & $38.6 \pm 21.1$ & $36.6 \pm 27.9$ \\
\hline
\end{tabular}

\footnotetext{
a Indicates significant difference between the Malays and the Chinese

${ }^{b}$ Indicates significant difference between smokers with more than 10 years of exposure and smokers with 1-5 years of exposure.

${ }^{\mathrm{c}}$ Data are Presented as Mean \pm SD
} 


\begin{tabular}{|c|c|c|c|c|c|}
\hline & Height & Weight & BMI, $\mathrm{kg} / \mathrm{m}^{2}$ & Body fat & WHR \\
\hline \multicolumn{6}{|c|}{ Total testosterone, $\mathrm{nmol} / \mathrm{L}$} \\
\hline Unadjusted & 0.057 & $-0.362^{b}$ & $-0.423^{b}$ & $-0.456^{b}$ & $-0.413^{b}$ \\
\hline Adjusted for age & 0.057 & $-0.314^{b}$ & $-0.41^{b}$ & $-0.375^{b}$ & $-0.248^{b}$ \\
\hline \multicolumn{6}{|c|}{ Free testosterone, $\mathrm{nmol} / \mathrm{L}$} \\
\hline Unadjusted & 0.063 & $-0.193^{b}$ & $-0.233^{b}$ & $-0.278^{b}$ & $-0.262^{b}$ \\
\hline Adjusted for age & 0.062 & -0.13 & $-0.207^{b}$ & $-0.164^{c}$ & -0.119 \\
\hline \multicolumn{6}{|c|}{$\begin{array}{l}\text { Non-SHBG bound testoster- } \\
\text { one, } \mathrm{nmol} / \mathrm{L}\end{array}$} \\
\hline Unadjusted & 0.068 & $-0.208^{b}$ & $-0.251^{b}$ & $-0.296^{b}$ & $-0.273^{b}$ \\
\hline Adjusted for age & 0.068 & -0.127 & $-0.204^{b}$ & $-0.163^{c}$ & -0.097 \\
\hline \multicolumn{6}{|c|}{ Total estradiol, $\mathrm{pmol} / \mathrm{L}^{\mathrm{a}}$} \\
\hline Unadjusted & 0.079 & -0.134 & $-0.174^{c}$ & $-0.176^{c}$ & $-0.144^{c}$ \\
\hline Adjusted for age & \multicolumn{5}{|c|}{ no nonparametric alternative } \\
\hline \multicolumn{6}{|c|}{ Free estradiol, pmol/L ${ }^{a}$} \\
\hline Unadjusted & 0.066 & -0.040 & -0.069 & -0.077 & -0.055 \\
\hline Adjusted for age & \multicolumn{5}{|c|}{ no nonparametric alternative } \\
\hline \multicolumn{6}{|c|}{$\begin{array}{l}\text { Non-SHBG bound estradiol, } \\
\mathrm{pmol} / \mathrm{L}^{\mathrm{a}}\end{array}$} \\
\hline Unadjusted & 0.064 & -0.051 & -0.080 & -0.086 & -0.065 \\
\hline Adjusted for age & \multicolumn{5}{|c|}{ no nonparametric alternative } \\
\hline \multicolumn{6}{|c|}{$\begin{array}{l}\text { Sex-hormone binding glob- } \\
\text { ulin, nmol/L }\end{array}$} \\
\hline Unadjusted & -0.023 & $-0.414^{b}$ & $-0.459^{b}$ & $-0.448^{b}$ & $-0.284^{b}$ \\
\hline Adjusted for age & -0.039 & $-0.461^{b}$ & $-0.496^{b}$ & $-0.480^{b}$ & $-0.261^{b}$ \\
\hline
\end{tabular}

\begin{tabular}{|c|c|c|c|}
\hline & $\begin{array}{l}\text { Predictor Included } \\
\text { Body Fat, \% }\end{array}$ & $\begin{array}{l}\text { Predictor Ex } \\
\text { BMI, kg/m² }\end{array}$ & WHR \\
\hline \multicolumn{4}{|c|}{ Total Testosterone } \\
\hline $\begin{array}{l}\beta^{b} \\
r^{2 c} \text { model }\end{array}$ & $\begin{array}{l}-0.456 \\
0.208^{a}\end{array}$ & -0.026 & -0.053 \\
\hline \multicolumn{4}{|c|}{ Free Testosterone } \\
\hline $\begin{array}{l}\beta^{b} \\
r^{2 c} \text { model }\end{array}$ & $\begin{array}{l}-0.279 \\
0.078^{\mathrm{a}}\end{array}$ & 0.132 & -0.064 \\
\hline $\begin{array}{l}\text { Non-SHBG bo } \\
\beta^{\mathrm{b}} \\
\mathrm{r}^{2 \mathrm{c}} \text { model }\end{array}$ & $\begin{array}{l}-0.297 \\
0.088^{a}\end{array}$ & 0.125 & -0.058 \\
\hline $\begin{array}{l}\text { SHBG (square } \\
\beta^{\mathrm{b}} \\
\mathrm{r}^{2 \mathrm{c}} \text { model }\end{array}$ & $\begin{array}{l}-0.172 \\
0.030^{a}\end{array}$ & 0.151 & 0.032 \\
\hline
\end{tabular}

a Significance with $P<0.001$

${ }^{\mathrm{b}}$ Standardized regression coefficient $(\beta)$ describes the extent of SD change of the sex hormones when the predictors of interest change by 1 SD while the other predictors are held constant.

${ }^{c} r^{2}$ of the equation is also shown to indicate the percentage of variation in sex hormones that can be explained by the equations generated.

one, $7.8 \%$ of the variation of free testosterone, $8.8 \%$ of the variation in bioavailable testosterone, and $3.0 \%$ of the variation in SHBG. Regression analysis was not conducted for estradiol levels, because the data were not distributed normally and because there was no nonparametric alternative (Table 4).

\section{Discussion}

Ethnic differences in the prevalence and incidence of diseases, such as diabetes mellitus (29), prostate cancer (30), and hip fractures (31), have been observed in Malaysia. For instance, according to the National Cancer Registry 2007, the Chinese population has a higher prevalence 
of prostate cancer compared with other ethnic groups in Malaysia (30). Because these diseases are associated with sex hormones, their prevalence may be attributed to variations of these hormones between races. Other factors, such as smoking $(15,17)$ and obesity $(22)$, should be taken into consideration, because they can also influence the levels of sex hormones in the body. However, the relationship between sex hormones and potential confounding factors has not been examined in the Malaysian population. The difference in testosterone levels between Chinese and Malay ethnic groups in Malaysia was not significant in this study, but the difference in estradiol levels was significant. Because these ethnic groups have not been compared, we do not have reference data for our findings. However, a similar observation was reported by Rohrmann et al. (2007), wherein serum estrogen levels were significantly higher in non-Hispanic black men compared with non-Hispanic white men in the United States (12). Determining whether this difference in estradiol levels explains the difference in the prevalence of diseases is beyond the scope of the present study._However, Malay men have a lower incidence of hip fractures compared with Chinese men in Malaysia (31). This may be attributed to the positive effects of estradiol in achieving higher peak bone mass during early adulthood. Since estradiol is produced largely by the conversion of endogenous testosterone by aromatase in men (32), the difference in estradiol levels between Malay and Chinese men may reflect a difference in the expression of this enzyme.

Diet can contribute to variations in sex hormones; thus, the difference in estradiol levels could also have been caused by distinct food intake patterns between groups $(16,33)$. Both factors need further study to explain the difference in estradiol levels between the two ethnicities.

Our finding of the lack of effect of smoking on sex hormone levels in apparently healthy young adult men is supported by several studies. Klaiber and Broverman (1988) found no significant difference in testosterone production rate or metabolic clearance rate of testosterone between smokers and non-smokers. They also recorded a significantly higher level of estradiol and its production rate in smokers versus non-smokers (20). Hautanen et al. also failed to note any differences in testosterone and estradiol levels in a mixed population of healthy subjects, dyslipidemic subjects, and subjects with heart disease (19). Harman et al. found no significant effect of smoking on total and free testosterone indices in men over a wide age range (18). There are other studies that indicate a higher testosterone level in smokers compared with non-smokers (15-17). The discrepancy between our results and the previous studies may be due to differences in the study populations (age range, ethnicity, and geographical variation) and the duration of exposure. Few studies with relatively small sample sizes have reported significantly lower testosterone levels in smokers versus non-smokers (14). Also, testosterone level is negatively associated with waist circumference/waist-hip circumference ratio and body fat. A previous study by van de Beld et al.(2000) in older males found a significant inverse relationship between fat mass and testosterone levels but not estradiol levels (34). Our findings not only confirm these findings but also imply that the influence of body adiposity on testosterone in men begins in early adulthood. This was confirmed by a study by Mauras et al. (1998), wherein decreased lipid oxidation and increased fat mass developed when the hypogonadal state was artificially induced in a group of young men (35), explaining why low testosterone and obesity are associated with many diseases, such as insulin resistance (10).

In our study, BMI did not correlate with any sex hormone level, perhaps because it is not an accurate estimation of adiposity, in which lean mass and fat mass are not differentiated. This causes men with muscular builds and low body fat to have high BMIs (36).

There are several limitations of this study. The subjects were not randomly selected; thus, selection bias hinders the generalization of our findings. The use of bioelectric impedance technology to estimate the percentage of total body fat did not reflect the distribution of body fat in each body part, but it is the most feasible body fat estimation technique in mobile data collection and is a better measurement of adiposity compared with BMI (36). The effect of passive smoking was not evaluated in this study, which could have influenced sex hormone levels in men and thus should be considered in future studies. Since this was a pilot study, a larger sample size would increase the power of the study and the validity of the results.

In conclusion, testosterone levels in young adult men in Malaysia are not influenced by ethnicity or smoking, but estradiol levels are higher in Malays and smokers with more than 10 years of exposure. Percentage of body fat is the most significant predictor of testosterone and SHBG. The results indicate that the percentage of body fat, ethnicity, and duration of exposure to cigarette smoke influence sex hormones and should be taken into consideration in the interpretation of sex hormone levels in future studies.

\section{Acknowledgements}

We would like to thank Universiti Kebangsaan Malaysia for providing financial support for this study and the Pharmacoepidemiology Unit, Department of Pharmacology, Faculty of Medicine, Universiti Kebangsaan Malaysia for providing statistical consultation.

\section{Financial Disclosure}

None declared.

\section{Funding/Support}

This study was supported by Arus Perdana Grant (UKMAP-TKP-09-2009) and postgraduate research fund (FF-3762010) provided by Universiti Kebangsaan Malaysia. 


\section{References}

1. Araujo AB, Travison TG, Leder BZ, McKinlay JB. Correlations between serum testosterone, estradiol, and sex hormone-binding globulin and bone mineral density in a diverse sample of men.J Clin Endocrinol Metab. 2008;93 (6) :2135-41.

2. Kuchuk NO, van Schoor NM, Pluijm SM, Smit JH, de Ronde W, Lips $P$. The association of sex hormone levels with quantitative ultrasound, bone mineral density, bone turnover and osteoporotic fractures in older men and women. Clin Endocrinol (Oxf). 2007;67 (2):295-303.

3. Paller CJ, Shiels MS, Rohrmann S, Basaria S, Rifai N, Nelson W, et al. Relationship of sex steroid hormones with bone mineral density (BMD) in a nationally representative sample of men. Clin Endocrinol (Oxf). 2009;70 (1) :26-34.

4. LeBlanc ES, Nielson CM, Marshall LM, Lapidus JA, Barrett-Connor $\mathrm{E}$, Ensrud KE, et al. The effects of serum testosterone, estradiol, and sex hormone binding globulin levels on fracture risk in older men. JClin Endocrinol Metab. 2009;94 (9) :3337-46.

5. Meier C, Nguyen TV, Handelsman DJ, Schindler C, Kushnir MM, Rockwood AL, et al. Endogenous sex hormones and incident fracture risk in older men: the Dubbo Osteoporosis Epidemiology Study. Arch Intern Med. 2008;168 (1) :47-54.

6. Svartberg J, von Muhlen D, Mathiesen E, Joakimsen O, Bonaa $\mathrm{KH}$ Stensland-Bugge E. Low testosterone levels are associated with carotid atherosclerosis in men.JIntern Med. 2006;259 (6) :576-82.

7. Yeap BB, Hyde Z, Almeida OP, Norman PE, Chubb SA, Jamrozik $\mathrm{K}$, et al. Lower testosterone levels predict incident stroke and transient ischemic attack in older men. J Clin Endocrinol Metab. 2009;94 (7): 2353-9.

8. Gann PH, Hennekens CH, Ma J, Longcope C, Stampfer MJ. Prospective study of sex hormone levels and risk of prostate cancer. J Natl Cancer Inst. 1996;88 (16) :1118-26.

9. Grossmann M, Thomas MC, Panagiotopoulos S, Sharpe K, Macisaac RJ, Clarke S, et al. Low testosterone levels are common and associated with insulin resistance in men with diabetes. J Clin Endocrinol Metab. 2008;93 (5) :1834-40.

10. Tsai EC, Matsumoto AM, Fujimoto WY, Boyko EJ. Association of bioavailable, free, and total testosterone with insulin resistance: influence of sex hormone-binding globulin and body fat. Diabetes Care. 2004;27 (4):861-8.

11. Orwoll ES, Nielson CM, Labrie F, Barrett-Connor E, Cauley JA, Cummings SR, et al. Evidence for geographical and racial variation in serum sex steroid levels in older men. J Clin Endocrinol Metab. 2010;95 (10) :E151-60.

12. Rohrmann S, Nelson WG, Rifai N, Brown TR, Dobs A, Kanarek N, et al. Serum estrogen, but not testosterone, levels differ between black and white men in a nationally representative sample of Americans. J Clin Endocrinol Metab. 2007;92 (7):2519-25.

13. Winters SJ, Brufsky A, Weissfeld J, Trump DL, Dyky MA, Hadeed $\mathrm{V}$. Testosterone, sex hormone-binding globulin, and body composition in young adult African American and Caucasian men. Metabolism. 2001;50 (10) :1242-7.

14. Shaarawy M, Mahmoud KZ. Endocrine profile and semen characteristics in male smokers. Fertil Steril. 1982;38 (2) :255-7.

15. English KM, Pugh PJ, Parry H, Scutt NE, Channer KS, Jones TH. Effect of cigarette smoking on levels of bioavailable testosterone in healthy men. Clin Sci (Lond). 2001;100 (6):661-5.

16. Field AE, Colditz GA, Willett WC, Longcope C, McKinlay JB. The relation of smoking, age, relative weight, and dietary intake to serum adrenal steroids, sex hormones, and sex hormone-binding globulin in middle-aged men.J Clin Endocrinol Metab.1994;79 (5) :1310-6.

17. Svartberg J, Jorde R. Endogenous testosterone levels and smok ing in men. The fifth Tromso study. Int J Androl. 2007;30 (3) :13743.

18. Harman SM, Metter EJ, Tobin JD, Pearson J, Blackman MR. Lon- gitudinal effects of aging on serum total and free testosterone levels in healthy men. Baltimore Longitudinal Study of Aging. $J$ Clin Endocrinol Metab. 2001;86 (2): 724-31.

19. Hautanen A, Manttari M, Kupari M, Sarna S, Manninen V, Frick $\mathrm{MH}$, et al. Cigarette smoking is associated with elevated adrenal androgen response to adrenocorticotropin. J Steroid Biochem Mol Biol. 1993;46 (2) :245-51.

20. Klaiber EL, Broverman DM. Dynamics of estradiol and testosterone and seminal fluid indexes in smokers and nonsmokers. Fertil Steril.1988;50 (4):630-4.

21. Ambrose JA, Barua RS. The pathophysiology of cigarette smok ing and cardiovascular disease: an update. J Am Coll Cardiol. 2004;43 (10): 1731-7.

22. Svartberg J, von Muhlen D, Sundsfjord J, Jorde R. Waist circumference and testosterone levels in community dwelling men. The Tromso study. Eur J Epidemiol. 2004;19 (7):657-63.

23. Bjornerem A, Straume B, Midtby M, Fonnebo V, Sundsfjord J, Svartberg J, et al. Endogenous sex hormones in relation to age, sex, lifestyle factors, and chronic diseases in a general population: the Tromso Study. J Clin Endocrinol Metab. 2004;89 (12) :6039-47.

24. Orwoll E, Lambert LC, Marshall LM, Phipps K, Blank J, BarrettConnor E, et al. Testosterone and estradiol among older men. J Clin Endocrinol Metab. 2006;91 (4):1336-44.

25. Chin KY, Ima-Nirwana S, Isa Naina M, Norazlina M, Ahmad Nazrun S, Norliza M, et al. Calcaneal Quantitative Ultrasound Value for Middle-Aged and Elderly Malaysian Chinese Men and Its Association With Age and Body Anthropometry. J Clin Densitom. 2012;15(1):86-91.

26. Karim NA, Kather HM. Nutritional Status and Food Habits of Middle-aged Adults in Selected Areas of Selangor. Malays J Nutr. 2003;9(2): :125-36

27. Keddissi JI, Younis WG, Chbeir EA, Daher NN, Dernaika TA, Kinasewitz GT. The use of statins and lung function in current and former smokers. Chest. 2007;132 (6):1764-71.

28. Sodergard R, Backstrom T, Shanbhag V, Carstensen H. Calculation of free and bound fractions of testosterone and estradiol-17 beta to human plasma proteins at body temperature. J Steroid Biochem.1982;16 (6):801-10.

29. Letchuman GR, Wan Nazaimoon WM, Wan Mohamad WB, Chandran LR, Tee GH, Jamaiyah H, et al. Prevalence of diabetes in the Malaysian National Health Morbidity Survey III 2006. Med J Malaysia. 2010;65 (3) :180-6.

30. Gerard LCC, Halimah Y. Second report of the national cancer Registry cancer incidence in malaysia. In: Malaysia $\mathrm{MoH}$, editor Kuala Lumpur; 2003.

31. Lee J-K, Khir ASM. The incidence of hip fracture in Malaysians above 50 years of age: variation in different ethnic groups. APLAR Journal of Rheumatology. 2007;10 (4):300-5.

32. Riggs BL, Khosla S, Melton LJ, 3rd. Sex steroids and the construction and conservation of the adult skeleton. Endocr Rev. 2002;23 (3) :279-302.

33. Longcope C, Feldman HA, McKinlay JB, Araujo AB. Diet and sex hormone-binding globulin. J Clin Endocrinol Metab. 2000;85 (1) :293-6.

34. van den Beld AW, de Jong FH, Grobbee DE, Pols HA, Lamberts SW. Measures of bioavailable serum testosterone and estradiol and their relationships with muscle strength, bone density, and body composition in elderly men. J Clin Endocrinol Metab. 2000;85 (9) :3276-82.

35. Mauras N, Hayes V, Welch S, Rini A, Helgeson K, Dokler M, et al. Testosterone deficiency in young men: marked alterations in whole body protein kinetics, strength, and adiposity.J Clin Endocrinol Metab. 1998;83 (6): 1886-92.

36. Snijder MB, van Dam RM, Visser M, Seidell JC. What aspects of body fat are particularly hazardous and how do we measure them? Int J Epidemiol. 2006;35 (1) :83-92. 